\title{
ÁREAS LIVRES PÚBLICAS - ESTUDO DE CASO DA MICRORREGIÃO 09 DEFINIDA PELA PREFEITURA MUNICIPAL DE EM PRESIDENTE PRUDENTE-SP
}

Jacqueline Magalhães Saab1, Letícia Bortolo Martins', Marcos Norberto Boin², MayaraPissutti Albano $^{1}$, Sibila Corral de Arêa Honda ${ }^{1}$, Fabrícia Dias da Cunha De Moraes Fernandes Borges ${ }^{1}$

${ }^{1}$ Universidade do Oeste Paulista - UNOESTE, curso de Arquitetura e Urbanismo, Presidente Prudente, SP.

²Universidade Federal da Grande Dourados - UFGD, Dourados, MS. E-mail: sibila@unoeste.br

\section{RESUMO}

A partir da segunda metade do século XX devido à intensa expansão territorial das cidades no Brasil, a apropriação de áreas públicas de forma desordenada e ilegal tem ocorrido. A ausência de um planejamento adequado também cooperou para perda de espaços livres, que são primordiais para estruturação das cidades, tanto nos quesitos ambientais e sanitários como em relação à qualidade de vida da população local. Com base em revisão bibliográfica, documental e levantamento físico territorial, esta pesquisa visa a identificar, levantar e mapear as áreas livres públicas da Microrregião Administrativa 09 da cidade de Presidente Prudente-SP, bem como verificar seus usos atuais.

Palavras-chave:Urbanização, Planejamento Urbano, Gestão Urbana, Áreas livres,Áreas Públicas.

\section{PUBLIC FREE AREAS- CASE STUDY OF MICROREGION 09 DEFINED BY PRESIDENTE PRUDENTE-SP CITY HALL}

\begin{abstract}
Sincethe second half of the twentieth century, due to the big territorial expansion of cities in Brazil,the appropriation of public areas in a disorderly and illegal has occurred. The lack of appropriate planning also cooperated with loss of open spaces, which are fundamental to the structuring of cities, both environmental and sanitarian aspects as the quality of life of the local population. Based on bibliographical and documental review and physical-territorial survey, this research has the objective of identify, measure and map open areas of administrative Microregion 09 of the city of PresidentePrudente-SP, as well as verify their current uses.
\end{abstract}

Keywords: Urbanization, Urban Planning, Urban Management, Free Areas, Public Areas. 


\section{INTRODUÇÃO E JUSTIFICATIVA}

O espaço livre, devido ao seu conceito abrangente, interdisciplinar e complexo, apresenta definições muitas vezes divergentes, sendo um termo abordado por inúmeros autores. Segundo Magnoli (1986) os espaços livres urbanos, visto como espaços livres de edificação, podem ser elencados em: jardins públicos ou privados, ruas e avenidas, praças e parques, matas, mangues e praias urbanas, ou simples vazios urbanos. Estes locais compõem um sistema complexo, visto apresentarem relações de conectividade e complementaridade.

De forma diversa, Nucci (2001)advoga que os espaços livres são um subgrupo do campo paisagístico urbano, que envolve entre outros conceitos os espaços abertos, áreas livres, áreas verdes, sistemas de áreas de lazer, cobertura vegetal e que,na verdade, também são largamente visados para conceituar espaços livres.

Observa-se que em virtude da diversidade desses espaços no ambiente urbano, estes conceitos abarcam discussões teóricas, especialmente quando se trata da escala de análise.

Todavia uma questão comum permeia as definições dos teóricos, trata-se da relevância e o papel crucial dos espaços livres públicos nas urbes. Tais espaços estão estreitamente atrelados a sociabilização, a mobilidade urbana, além fomentarem aqualidade ambiental e sanitária traduzindo em melhorias na qualidade de vida para a comunidade, além do caráter estético atribuído ao lugar (CUNHA, 2003).

É patente que a expansão das cidades brasileiras, sendo norteadas por leis e diretrizes que conduzissem a ocupação de forma correta, deixaram a desejar no quesito de aplicação durante a execução, culminando na ocupação dos espaços de forma não apropriada (MARICATO, 2013). Dessa forma, a implantação de áreas urbanas, com intuito de gerar um sistema de espaços livres públicos coeso e completo, não ocorreu (MENNHE e COELHO, 1999).

Mesmo diante da Lei Federal 6.766/79, que implementou o controle do uso, ocupação e parcelamento do solo urbano, atribuindo a responsabilidade de planejamento e gestão da área da cidade a esfera municipal, nota-se as prefeituras negligenciaram distribuição e as formas de ocupação dos espaços livres.

Portanto, a presente artigo visa a aprofundar os conhecimentos sobre áreas livres públicas, com ênfase na Microrregião 09 na cidade de Presidente Prudente - SP, de forma a averiguar e mapear as irregularidades de uso. Importante destacar que a cidade de Presidente Prudente foi dividida em 18 Microrregiões Administrativas pela Prefeitura Municipal, não oficialmente, para possibilitar e facilitar os levantamentos da própria Prefeitura e do Ministério Público, relativas a 
falta de áreas públicas aprovadas legalmente e com usos alterados, conforme consta no Inquérito Civil - IC No MP : 14.0720.0000322/2.011-1.

A Microrregião 09 localiza-se na zona sudoeste da malha urbana e é composta pelos seguintes bairros: Jardim dos Pioneiros,JardimBongiovani,VilaLiberdade,JardimMorishita,Cidade Universitária e por três fragmentos do Parque do Povo denominados de primeiro, segundo e terceiro trecho (Figura 1).

O objetivo do presente trabalho éanalisar os espaços livres públicos e institucionais na Microrregião 09 na cidade de Presidente Prudente, afim de averiguar sua utilização atual, incompatibilidade com a legislação competente.

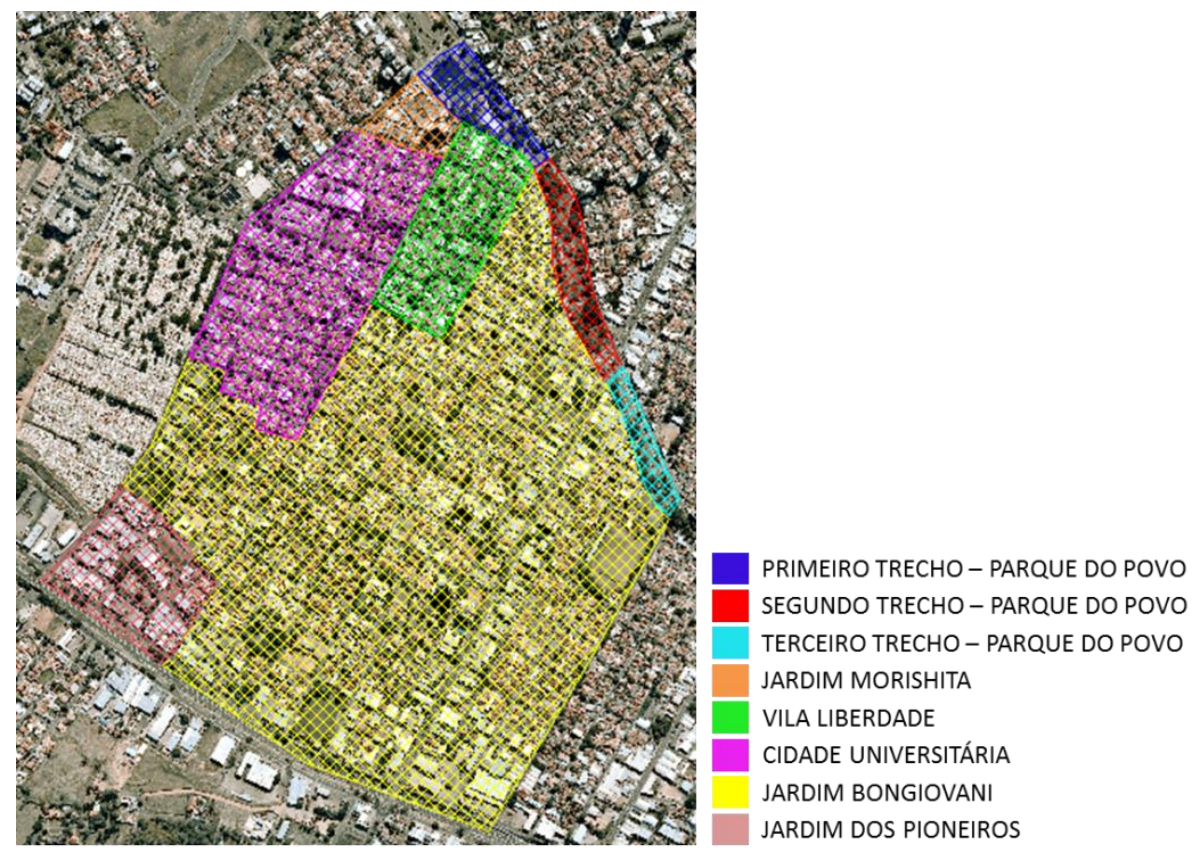

Figura 1 - Limites da Microrregião 09 e respectivos bairros

Fonte: Autores, 2014.

\section{METODOLOGIA}

A metodologia, de cunho qualiquantitativa, utilizou-se de levantamento bibliográfico, de pesquisa documental, de levantamentos físico territoriais urbanísticos das áreas livres públicas e áreas institucionais da cidade de Presidente Prudente - SP.Os mapeamentos foram realizados através do softwarespring.

\section{DISCUSSÃO}

As áreas verdes possuem diversos conceitos quanto ao seu uso, função e tamanho. Há autores que consideram áreas verdes, áreas livres que possuam espécies vegetais, independentes 
do seu porte, como por exemplo as praças, jardins públicos e parques urbanos. Outros autores afirmam que áreas verdes devem possuirvegetação vertical expressiva, com característica pública ou privada e que sejam aproveitadas com finalidades sociais, ecológicas, científicas ou culturais.

Nucci (2008) alega que área verde necessita oferecer, no mínimo, 70\% de cobertura vegetal e solo permeável, cumprindo função estética, ecológica e de lazer; já Grey e Deneke (1986) denominam deárea verde pequenos espaços de rua, parques e jardins em torno de edifícios públicos ou privados, permeáveis que possuam vegetação, afirmação que Lima (et al, 1994) discorda.

Contudo para o presente trabalho considerou-se área verde "a de propriedade pública ou particular, delimitada pela prefeitura, com o objetivo de implantar ou preservar arborização e ajardinamento, visando manter a ecologia e resguardar as condições ambientais e paisagísticas" (GEIGERet al., 1975, apud NUCCI, 2001).

Áreas Verdes distinguem-se da paisagem de concreto, pela sua tendência de dissipar a radiação solar, através da evaporação e transpiração. Na cidade, concreto, pedra, tijolo e asfalto substituem a cobertura vegetal natural do campo. Esses materiais absorvem o calor mais rapidamente e o mantém em maiores quantidades do que as plantas, o solo e a água. (SPIRN, 1995, apud BENINI eMARTIN, 2010).

Benini eMartin (2010) afirmam que entre os benefícios trazidos às cidades pelas áreas verdes estão: a criação de microclima mais ameno, despoluição do ar de partículas sólidas e gasosas, redução da poluição sonora, purificação do ar pela redução de microorganismos, redução da intensidade do vento canalizado em avenidas cercadas por prédios. Destacam também a conservação da umidade do solo, a ajuda na absorção da água pluvial, sensação bem-estar para a população e causa grande impacto quando comparadas com os edifícios construídos a sua volta, e que é possível encontrar um ambiente agradável nas áreas verdes, propiciando à população a integração com a natureza e distanciando da inquietude da cidade.

Assim como as áreas verdes são importantes para as cidades, as áreas institucionais também oferecem benefícios inúmeros à população. Áreas institucionais são espaços dedicadosà instalação de equipamentos públicos e comunitários como creches, unidades de saúdes, ginásios esportivos, escolas, delegacias, prédios administrativos municipais, entre outros. Esses ambientes devem atender as necessidades básicas das pessoas que moram em seu entorno (BENINIEMARTIN, 2010)

Àpartir da segunda metade do século XX, o processo de urbanização brasileiro se tornou ainda mais acelerado, gerando enorme movimento de construção da cidade legal e ilegal. No 
entanto, tal crescimento não respondeu satisfatoriamente todas as necessidades urbanas, como moradia, trabalho, abastecimento, saúde, energia e lazer (MARICATO, 2013).

Buscando melhorar e controlar o Parcelamento do Solo urbano, é outorgada em 1979 a Lei Federal 6.766. O parcelamento do solo baseia-se em organizar o crescimento das cidades, entretanto não se deve levar em conta apenas a atividade econômica gerada a partir dos lotes urbanos, mas também as questões relacionadas com a estética, sanidade, segurança e educação. Por fim essas áreas devem apresentar boas condições à população, colaborando com a qualidade de vida nas urbes.

Segundo a Lei supracitada, as áreas destinadas a espaços livres e equipamentos urbanos devem ser registradas em Cartório (art. 20) e passam a integrar o domínio do Município (art. 22). A mesma Lei não estabeleceu exceções à hipótese de reserva de áreas destinadas à construção de equipamentos urbanos e comunitários e foi enfática ao subordinar a aprovação da localização destas, bem como da descrição de percentuais da área total da gleba a ser loteada, pelo poder público municipal.

Em Presidente Prudente a Lei Complementar № 154/2008, que dispõe dobre o parcelamento do solo urbano em Presidente Prudente, em seu artigo 12, determina que os loteamentos deverão destinar entre 5\% (cinco por cento) e 10\% (dez por cento) da área loteável para áreas institucionais, e entre 10\% (dez por cento) e 15\% (quinze por cento) da área loteável para áreas verdes.

No entanto através das pesquisas realizadas constatou-se irregularidades nos bairros que compõem a Microrregião 09, os resultados serão apresentados no próximo item.

\section{RESULTADOS}

Através das pesquisas documentais e físico territoriais in locu, foram levantadas a situação das áreas verdes e das áreas institucionais da Microrregião 09.

\section{JARDIM BONGIOVANI}

O bairro não possui área institucional determinada pela prefeitura. Em contrapartida, possui $8 \%$ deáreas verdes, além de ser uma porcentagem abaixo da lei,essas áreas não estão sendo usadas adequadamente. Suas praças possuem trailers. Outras áreas maiores foram transformadas em campos de futebol cercado, sem que a população tenha livre acesso. 


\section{JARDIM DOS PIONEIROS}

O Jardim dos Pioneiros situa-se entre o Jardim Bongiovani e a Rodovia Raposo Tavares. De acordo com o mapa da prefeitura, o bairro possui $11 \%$ de áreas verdes e apenas uma área institucional, resultando $5 \%$ das áreas loteáveisporém todas estão sendo ocupadas irregularmente. As áreas verdes possuem construções e comércios particulares, enquanto na área institucional se encontra a Companhia de Saneamento Básico do Estado de São Paulo - SABESP.

\section{CIDADE UNIVERSITÁRIA}

O bairro está situado entre o Jardim Morishita, Vila Liberdade e Jardim Bongiovani. Segundo dados da Prefeitura Municipal, o bairro não possui áreas institucionais e apenas $8 \%$ de área verde, porém após os estudos, foram encontrados o Tiro de Guerra e uma escola Municipal. Já no lugar das áreas verdes foram encontradas edificações. A única área verde legitima possui uma rua que a atravessa, cortando a praça, totalizando $1 \%$ das áreas loteáveis.

\section{JARDIM MORISHITA}

O bairro está situado entre a Cidade Universitária, o Parque do Povo e a Vila Liberdade. Possui residências e pontos comerciais. Não foram encontradas áreas verdes e nem áreas institucionais.

\section{VILA LIBERDADE}

O bairro está localizado entre a Cidade Universitária, Parque do Povo, Jardim Morishita e Jardim Bongiovani. Segundo dados da Prefeitura Municipal, o bairro não possui áreas institucionais e áreas verdes. Após os estudos, foi constatado a ausência de ambas as áreas.

\section{PARQUE DO POVO}

O Parque apresenta uma imensa área verde localizada desde a Avenida Manoel Goulart até a Avenida Brasil. Possui mobiliários urbanos como pista de skate, academia da terceira idade e playgrounds.

Seu primeiro trecho localiza entre a Avenida da Saudade e a Rua Donato Armelin. Esse espaço apresenta quiosques irregulares.O segundo trecho se localiza entre a Rua Donato Armelin a Avenida Coronel Marcondes. O trecho não apresenta irregularidades.O terceiro trecho se localiza entre a Avenida Coronel Marcondes, a Rua José Foz, a Avenida Brasil e a Rua Daniel Martins. O trecho se encontra regular. 


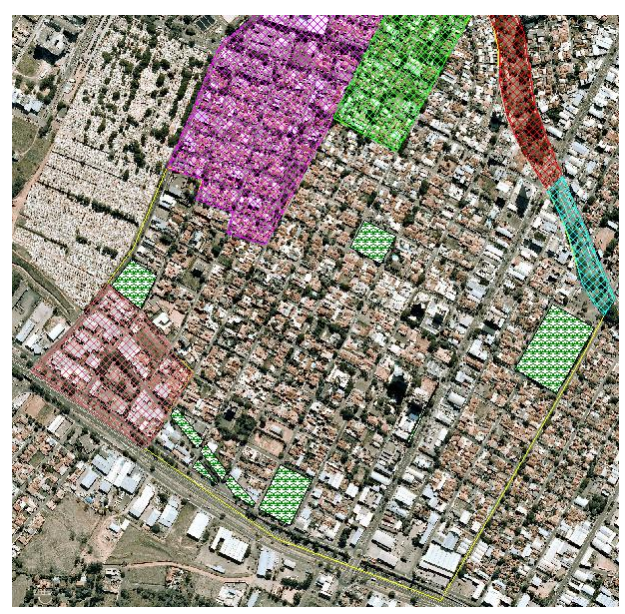

Figura 2-Jardim Bongiovani

Fonte: Autores, 2014.

Jardim Bongiovani

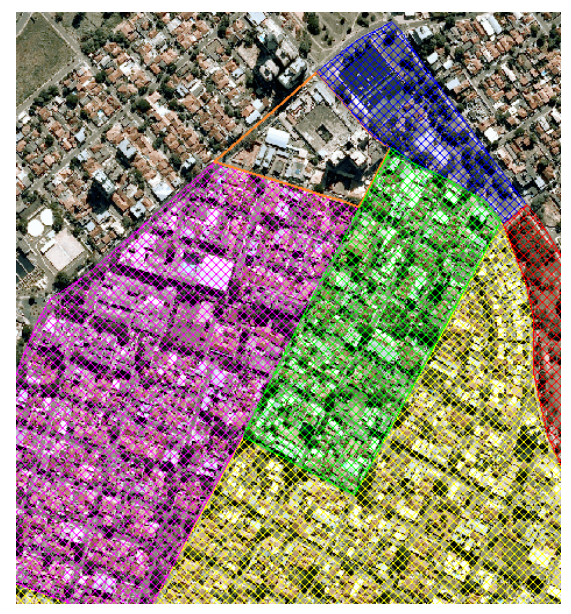

Figura 4-Jardim Morishita

Fonte: Autores, 2014.

Jardim Morishita

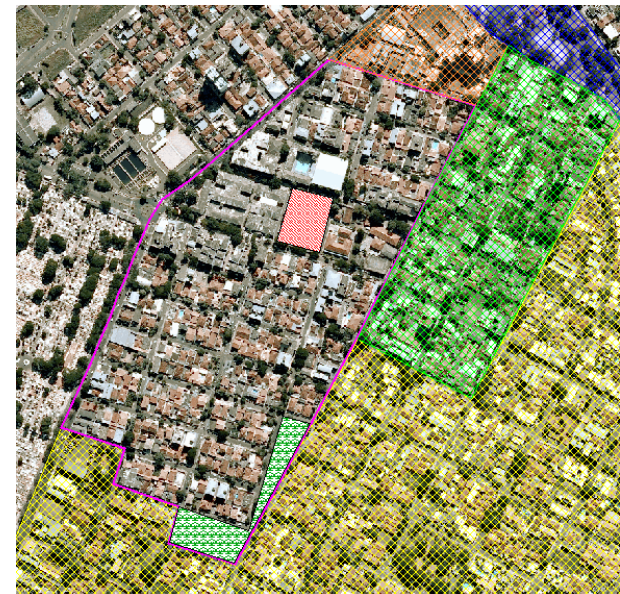

Figura 3-Cidade Universitária

Fonte: Autores, 2014.

Cidade Universitária

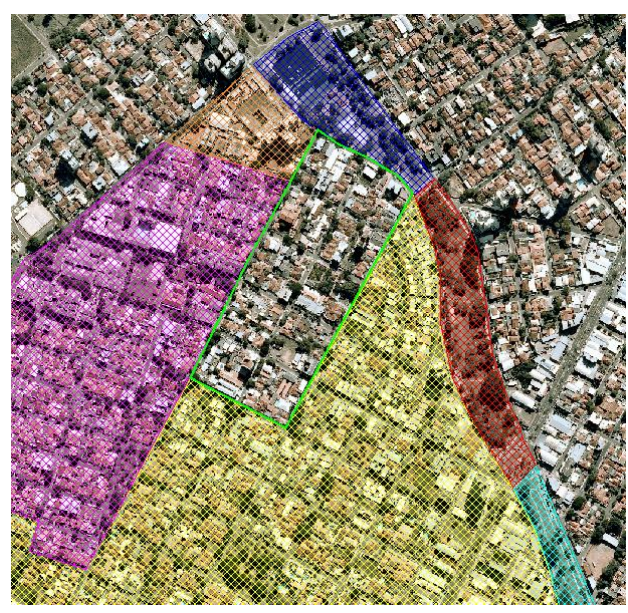

Figura 5-Vila Liberdade

Fonte: Autores, 2014.

Vila Liberdade 


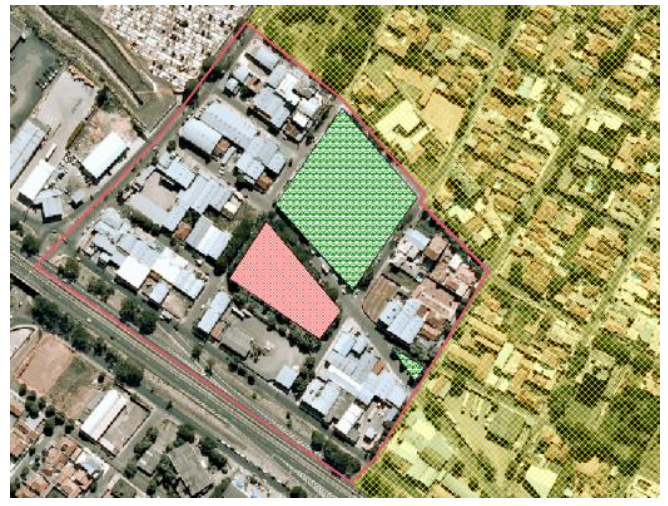

Figura 6-Jardim dos Pioneiros

Fonte: Autores, 2014.

Jardim dos Pioneiros

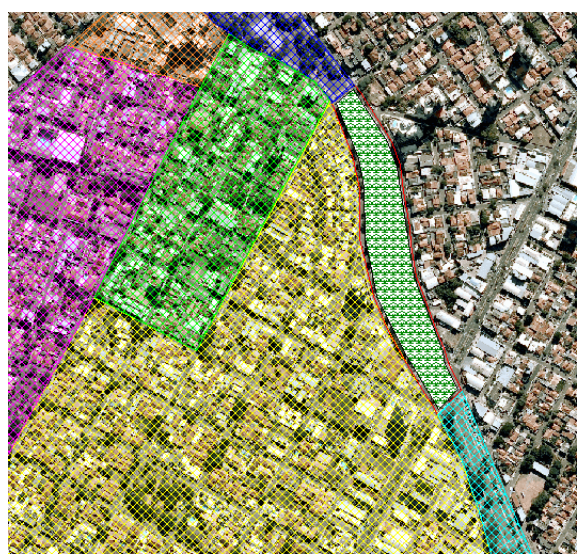

Figura 8-Segundo Trecho - Parque do Povo Fonte: Autores, 2014.

Segundo trecho - Parque do Povo

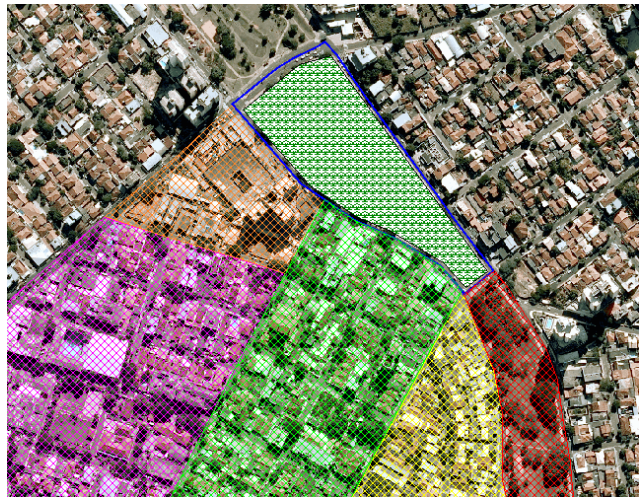

Figura 7-Primeiro trecho - Parque do Povo Fonte: Autores, 2014.

\section{Primeiro trecho - Parque do Povo}

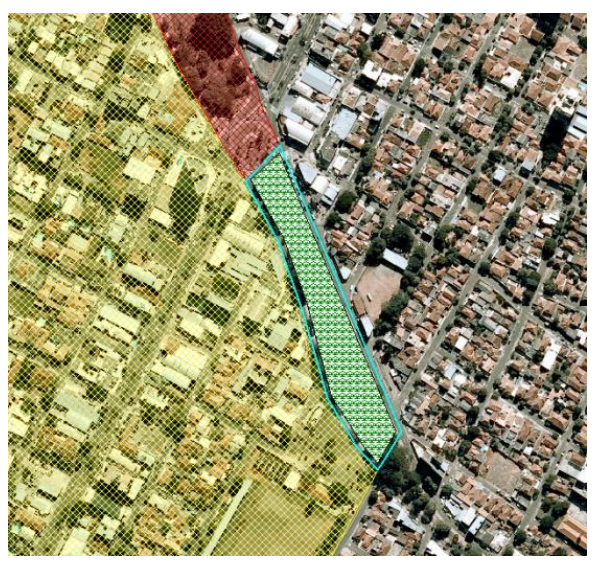

Figura 9-Terceiro Trecho - Parque do Povo Fonte: Autores, 2014.

Terceiro trecho - Parque do Povo

Áreas Verdes

Áreas Institucionais

A partir das análises dos diferentes conceitos apresentados, concluiu-se que as áreas verdes e institucionais são indispensáveis no contexto das cidades. No entanto, na cidade de Presidente Prudente - SP, em especial na Microrregião 09, não se tem dado a devida importância, visto que muitas se encontram em desconformidade com a lei.

É necessário que haja um cuidado especial com tais áreas e que a população residente nesse espaço seja recompensada de alguma forma por essa falta que pode comprometer a qualidade de vida local. 


\section{REFERÊNCIAS}

BENINI, Sandra Medina; MARTIN, Encarnita Salas. Decifrando as Áreas Verdes Públicas. Revista Formação. № 17, Volume 2, 2010.

BRASIL. Lei n.6.766, de 19 de dezembro de 1979. Dispõe sobre o parcelamento do solo urbano e dá outras providências.

CUNHA, Rita Dionde Araújo. Os espaços públicos abertos e as leis de uso e ocupação do solo: uma questão de qualidade para ambientes sustentáveis. III Enecs - Encontro Nacional sobre Edificações e Comunidades Sustentáveis. 2003.

LIMA, AnaMaria Liner Pereira et al. Problemas de utilização na conceituação de termos como espaços livres, áreas verdes e correlatos. In. 2ำ Congresso Brasileiro Sobre Arborização Urbana, 1994, ANAIS...São Luís. p. 539-550. Disponível em: http://www.labs.ufpr.br/site/wpcontent/uploads/2014/07/lima_anaisdecongressos_cbau_1994.pdf. Acesso em: 20.jun. 2015

LOBODA, Carlos Roberto; ANGELIS, Bruno Luiz Domingos De. Áreas Verdes Públicas Urbanas: Conceitos, Usos e Funções.Ambiência Guarapuava, PR. № 1, Volume 1. 2005.

MAGNOLI, Miranda, M. O parque no desenho urbano.In:TURKIENICZ, B. \& MALTA, M. Desenho urbano, Anais do II SEDUR, São Paulo, PINI/ FINEP, CNPq, 1986. p. 111- 120.

MARICATO, Ermínia.Brasil cidades: alternativas para a crise urbana.Petrópolis, RJ: Vozes, 7ạ ed., 2013.

MENNHE, M. H. \& COELHO, A. M. Características do sistema de parques públicos urbanos da cidade de São Paulo. In: ENTAC, 8, 2000, Salvador. ANAIS, Salvador: ANTAC., 2000. 8 p. CD-ROM. Seção artigos.

MINISTÉRIO PÚBLICO ESTADUAL. Inquérito Civil - IC No MP: 14.0720.0000322/2.011-1.

NUCCl, João Carlos. Qualidade ambiental \& adensamento urbano: um estudo de Ecologia e Planejamento da Paisagem aplicado ao distrito de Santa Cecília (MSP).São Paulo: Humanitas/ FFLCH-USP, 2001.

$\mathrm{NUCCl}$, João Carlos. Qualidade ambiental e adensamento urbano: um estudo de ecologia e

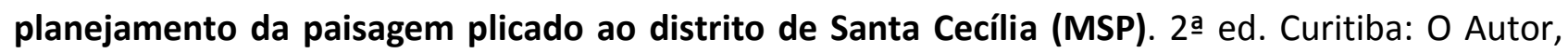
2008. 150 p. Disponível em: http://www.labs.ufpr.br/site/arquivos/qldade_amb_aden_urbano.pdf. Acesso em: 15abr. 2015.

PRESIDENTE PRUDENTE. Lei n.154, de 10 de janeiro de 2008. Dispõe sobre a Lei de Parcelamento do Solo para FinsUrbanos e dá outrasprovidências. 